\title{
Preface
}

\section{Studies in institutional translation and international legal communication}

This special issue is the second of two volumes devoted to research on legal discourse and translation, most of which was presented in the 2018 Transius International Conference on Legal and Institutional Translation at the University of Geneva's Faculty of Translation and Interpreting. The four papers of this volume focus on the interfaces between institutional translation and international legal communication. They provide a representative overview of approaches to these issues, including at EU and intergovernmental institutions, and the multiple facets and challenges of creating and applying multilingual instruments across borders. The selected studies also illustrate the fruitfulness of corpus-based methods grounded on legal analysis in this field, as well as the relevance of supplementing and enriching data with various institutional sources.

The first paper, "Legal-linguistic profiling in institutional contexts: The case of EU staff representation bodies", by Colin ROBERTSON (former lawyer-linguist at the Council of the EU), combines documentary research and a questionnaire as the starting point to define the scope of EU staff representation bodies, and their approaches to multilingual communication and translation. By applying a structured legal-linguistic profiling approach to contextualizing translation work, the study identifies a few differences and several commonalities between staff committees and trade unions, including, among the latter, the diversity of topics, textual genres and discourse styles covered in translation.

In "Epistemic modality: A corpus-based analysis of epistemic markers in EU and Polish judgments", Dariusz KOŹBIAŁ (University of Warsaw) explores a more specific aspect of EU legal communication, namely, markers of epistemic modality in English and Polish-language judgments of the Court of Justice of the EU, and how they compare to (non-translated) judgments of the Supreme Court of Poland. The analysis of these markers in 200 judgments of each group points to a high level of intra-generic convergence, which is more pronounced in adverbial epistemic markers than in verbal markers. The study confirms that this salient feature of judicial reasoning may be considered as idiomatic when 
translating EU judgments into Polish.

The third paper, "The transposition of international criminal law concepts into national jurisdictions: The case of genocide", also examines a subject related to the connection between international and national legal discourses, in this case in the area of criminal law. The author, Marie-Hélène GIRARD (University of Geneva), focuses on the concept of genocide to illustrate the nature and implications of legal transposition processes in this area. The corpus analyzed comprises 75 legal definitions of the concept in English, French and Spanish in 71 of the 131 States that had transposed the concept into their national legal systems as of November 2018. The semantic shifts identified confirm the transforming effects of transposition and translation processes, with variations that seem to correlate to differences in the languages and legal traditions of each jurisdiction.

In the last paper, "Facing translation errors at international organizations: What corrigenda reveal about correction processes and their implications for translation quality", the guest editor sheds light on a subject that is also largely unexplored in the field. After a review of error correction procedures in three illustrative settings (the EU institutions involved in law-making, the United Nations and the World Trade Organization), the analysis of translation-triggered corrigenda published in two target languages, French and Spanish, by these institutions in 2005, 2010 and 2015 yields results on the number, type and severity of errors corrected, as well as their density per textual genre. A distinction is made between content reformulation corrections and minor formal corrections in order to measure their diachronic changes and their semantic impact. The implications of the findings for translation quality assurance and legal certainty are also discussed in light of contextual information gathered from institutional language services, particularly with regard to the growing number of corrigenda to EU legal acts.

My gratitude goes, once again, to Aleksandra Matulewska (editorin-chief) and Emilia Wojtasik-Dziekan (co-editor) for their continued support through the editing process, as well as to all the authors and reviewers for their valuable contributions and cooperation.

Fernando PRIETO RAMOS

Guest editor of the special issue

Centre for Legal and Institutional Translation Studies (Transius)

Faculty of Translation and Interpreting (FTI)

University of Geneva, Switzerland

December 2019 